\title{
The Challenges Facing Arab Students with Learning Disabilities in Higher Education Institutions and the Role of Support Centers in Their Academic Functioning: A Preliminary Study
}

\author{
Dorit Olenik-Shemesh ${ }^{1}$, Tali Heiman ${ }^{1} \&$ Alla Assaig ${ }^{1}$ \\ ${ }^{1}$ Psychology and Education Department, The Open University of Israel, Israel \\ Correspondence: Dorit Olenik-Shemesh, Psychology and Education Department, The Open University of Israel, \\ Israel.E-mail: doritol@ac.il
}

Received: May 18, 2020

Accepted: July 2, $2020 \quad$ Online Published: October 23, 2020

doi:10.5539/ies.v13n11p44

URL: https://doi.org/10.5539/ies.v13n11p44

\begin{abstract}
The topic of support for students with learning disabilities (LD) has been studied to a considerable extent in recent years, due to the significant increase in the integration of students with learning disabilities in higher education institutions (HEI). However, there is hardly any research examining the support for students with learning disabilities in Israel's Arab sector. The purpose of the current preliminary study is to examine whether support centers for students with learning disabilities assist Arab students with their learning and general academic functioning in Israeli higher education institutions. The study is qualitative, involving semi-structured interviews with eight Arab students diagnosed with learning disabilities studying at two institutions of higher education. Analysis of the interviews revealed four major themes: The double difficulty that students experience due to the fact that they are Arabs for whom Hebrew is a second language, and due to their learning disabilities; lower awareness of learning disabilities in the Arab sector in Israel; post-diagnosis relief; a sense of wellbeing satisfaction with the educational, social and occupational support provided, enabling them to study and succeed. The article addresses also to the limitations of the study as a primary study, along with recommendations for further research based on this preliminary study.
\end{abstract}

Keywords: higher education, support centers, learning disabilities, Arab students in Israel

\section{Introduction}

The purpose of the current study is to examine whether support centers for students with learning disabilities help Arab students with learning disabilities who attend higher education institutions (HEIs) to improve their academic achievements, conduct and integration into higher education in Israel.

The number of Arab students in HEI in Israel has been on the rise in recent decade, leading to a social change in their integration into society. HEI offer a significant opportunity for Arab students to integrate economically, culturally and socially (Ali \& Daas, 2018). However, Arab students in HEI who are diagnosed with learning disabilities (LD) face a variety of difficulties beyond dealing with their specific disabilities and their implications, and are obliged to invest a great deal of physical and mental effort in order to achieve this integration.

Over the years, HEI have developed support programs for Arab students in general and for those with LD in particular. In Israel, a holistic program to make higher education more accessible to Arab society is being implemented and currently every HEI in Israel is obliged to manage a support unit for Arab students and to the Arab students' needs (Hendin \& Ben-Rabi, 2015). This holistic program is combined with programs that help all students with LD, constitutes a potentially significant force that helps students in HEI integrate into society and places of employment and provides support for all the difficulties experienced by Arab students in general, and especially those with LD. However, no research has yet examined the contribution of these programs to students' learning functioning and achievements. Thus, this preliminary study seeks to address whether support centers for students with LD assist Arab students improve their academic learning and academic function and achievements.

This main aim of the study is to reveal students' attitudes towards the support centers, indicating their contribution, in order to understand the existing situation as well as to develop new ways to improve the assistant for students from the Arab sector. More specifically, the study disclose how Arab students with LD cope with academic studies, the assistance provided by the support centers within HEI in Israel, and the response they provide (or do not 
provide) to the needs of Arab students with LD.

\subsection{Learning Disabilities Among Higher Education Students}

Learning disabilities are characterized with a as a various difficulties in learning and in the use of academic skills. Four parameters must be met for a LD to be diagnosed according to the APA (2013): (1) Difficulties in learning and use of skills and the presence of at least one of the following symptoms for at least 6 months: Reading inaccurately or slowly and strenuously, difficulty comprehending the meaning of a text, difficulty in spelling, in written expression; difficulty in mastering the meaning of numbers, numerical facts, calculation, or mathematical reasoning. (2) Academic skills are significantly and quantitatively impaired below what is considered age appropriate, cause significant disruptions to academic performance and to activities of daily living. (3) Identifying the disabilities is based on a gap of two years or more in the individual's ability to read and/or write and/or do math, compared to someone whose intelligence level is normal, when given sufficient opportunity to learn. (4) These difficulties are not explained by other factors such as a mental delay, brain damage, sensory perception disorder or an emotional problem. These difficulties appear mainly at school age, when the difference in the child's academic behaviors is first noticeable when compared to the peer group (APA, 2013). Similar to the previous definitions, the definition listed in the DSM-5, which replaces the one in the DSM-4, assumes that learning disabilities are neuro-developmental disorders that have a biological basis with cognitive repercussions. The interplay between genetic and environmental factors is reflected in the brain's ability to function effectively and accurately in tasks involving perception, verbal and nonverbal information processing, and learning. The results of learning disabilities are persistent disorders affecting functions such as: reading, reading comprehension, written expression, spelling, mathematical calculations and mathematical logic (Margalit, 2014).

There are several types of learning disabilities. The most common and well-known disability is a reading disorder, dyslexia. Nowadays, 21 different types of dyslexia are known, each caused by a disability at a different stage of the reading process, causing different types of errors and reading difficulties (Friedmann \& Coltheart, 2016). In most cases dyslexia has also been found to result in difficulties in acquiring spoken language, reading and spelling accompanied by errors in letter identification and clarification (Alt et al., 2017).

Another common disability is dysgraphia, defined as a dysfunction or a difficulty in producing written language in the context of handwriting mechanics (Erhardt \& Meade, 2005). It involves difficulties in acquiring writing skills or writing is below the expected level compared to the peer group (Dohla \& Heim, 2016). According to the DSM-5 definition, this disability is defined as a specific three-pronged learning disorder: difficulty in accurate spelling, difficulty with grammar, accuracy, punctuation, or clarity, and difficulty in organizing written expression (APA, 2013).

A relatively common third disability is dyscalculia, refers to problems with mathematical calculations and concepts, which manifests in the computational ability of learning standard arithmetic, and is defined as a difficulty in performing basic operations, despite the proper level of intelligence.

All three main types of disabilities can appear at different levels (Rapin, 2016). The disability may appear on its own or together with another one. The disability is determined by examining the individual compared with their age group and level. In addition to learning difficulties, difficulties in other areas arise that cause insecurity, emotional distress, low self-esteem, feelings of loneliness and behavioral problems. These are mutually influential criteria as they impinge on the intensity of the learning difficulty and sometimes can also exacerbate the behavior (Ziv, 2014).

Learning disabilities may be diagnosed throughout the developmental period from preschool onwards and students with LD may have a variety of difficulties that continue to accompany them later in life. Over the last two decades, research interest in studying adults with $L D$ has grown, with the realization that learning disabilities remain present throughout one's life cycle. Some symptoms diagnosed at younger ages change over time, some decrease, some become more severe and sometimes new symptoms not expressed earlier can appear among adults. Studies have shown that adults with LD may sometimes misunderstand social situations or display dependence on others. In addition they may often present shyness, stress, anxiety, loneliness, depression and low self-esteem, since they fear that others will discover their weaknesses (Howarth, Morris, Newlin, \& Webber, 2016). Einat and Einat (2004) mention reactions of despair and frustration with academic failure, aggression and helplessness when it comes to the education system, a feeling of being neglected by the educational establishment and a close connection between these factors and sometimes dropping out at middle school age and even lapsing into delinquent behavior. All of these may coexist with difficulty in integrating into the social-employment world.

Part of entering the adult world includes acquiring higher education. For students with LD, entry into higher education is a new arena fraught with new challenges and difficulties, and yet, in recent years, we have seen a 
significant increase in the number of students with LD studying in HEIs (Zeng, Ju, \& Hord, 2018). Yet, students with LD entering higher education face a number of notable common difficulties: the first is admission into the HEI. Generally speaking, this relates to childhood and adolescence with repeated academic failures and low achievements which block entry into higher education (Dahan, Meltzer, \& Finkelstein, 2011). Showers and Kinsman note that the odds of adults with LD or emotional and behavioral problems being able to study in higher education are 70\% lower than those without these disabilities (Showers \& Kinsman, 2017).

The second area relates to the difficulties experienced by students with LD during their academic studies. Once in HEIs, they encounter new demands compared with school. There are no classes organized according to one's age group, no 'homeroom teachers', and no special professional therapists; there is less personal attention and the learning environment makes it hard for them due to large and crowded classrooms which create a lot of noise and interference that impairs concentration and the ability to cope with future educational tasks (Couzens et al., 2015).

The third difficulty relates to the scope of study, the material and type of assignments required. Many of these students have been found to have difficulty with academic skills, as well as in the planning and organization of theoretical and academic writing (Dahan, Meltzer, \& Hadas-Lidor, 2010). Another academic difficulty faced by students with LD is that of understanding texts and instructions when doing coursework and exams, and many of them also have problems with time management and general organization. It is important to stress that these difficulties are particularly evident during the first year of study. The many difficulties, along with the lack of accommodations, lead to a great deal of dropout during the first year (Dahan, Meltzer, \& Finkelstein, 2011; Hadley, Hsu, Addison, \& Talbott, 2020). Showers and Kinsman (2017) showed that 24.7\% of students with LD dropped out as early as the first year and the dropout rate was $50.6 \%$ by the third year. In the absence of effective learning skills, students with LD are at a high risk of failing in their academic assignments. The difficulties they face when it comes to learning, understanding and applying the study material impair their academic achievements, their academic ability and even causes exam anxiety (Weis, Speridakos, \& Ludwig, 2014).

Alongside the academic difficulties, they also experience emotional difficulties and a sense of helplessness. Thus, some students with LD find it difficult to engage in social interactions and sometimes have to deal with their learning tasks alone (Couzens et al., 2015). Trigger, Egozi, Doron, and Elharar (2003), found that students with LD had lower self-esteem than other students. Roer-Stryar (2003) also noted that students with LD are more likely to experience high levels of anxiety and stress. Due to the lack of proper arrangements by the HEI to cater to their unique needs, these students often fail academically and this can lead to depression. They also have difficulty meeting tight schedules and thus, a sense of despair due to the accumulated pressure. Einat (2004) added that they also experience feelings of being lost everywhere, difficulty in remembering study material and expressing it comprehensively, specific difficulties with mathematics and English, and have a sense of inability to succeed despite the considerable effort invested by them (Einat, 2004).

Margalit, Brezhnitz, and Aharoni (1998) divided these difficulties into several categories: difficulties with spoken language, reading, writing, mathematics, other learning skills, attentiveness, self-image and self-confidence. These significant difficulties distinguish between students' potential theoretical abilities and their realization. A basic reading disability does, indeed, impair a student's ability to handle written reference materials and reduce the ability to keep up a reasonable studying pace, and The range of disabilities may be wide (Einat, 2004).

In order to integrate into academic studies, students with a learning disability must invest great physical effort-more study hours than other students without disabilities, and mental efforts that include coping with frustration, lowered self-esteem when comparing themselves to those around them. Ultimately, despite the students' struggles and the accommodations they receive in the HEI, they often experience relative failure. To this is also added the concern of the low prospects of successfully integrating into compatible employment after academic studies (Einat, 2004). It seems, therefore, that entry into higher education entails difficulties and challenges for students with LD in a variety of both emotional and academic areas.

\subsection{Support Centers in Higher Education Institutions for Students with Learning Disabilities}

In recent decades, students with different types of learning disabilities have begun to integrate into HEI. Many of these around the world as well as those in Israel have, over the years, developed support centers to help students with LD throughout their years of study so that they can succeed in attaining the degree they aspire to. Currently there are support centers in most HEIs in Israel, as law now demands. Initially, the programs for students with LD focused primarily on the short term, including help and learning skills development directed at the entire student population. Later, when the number of students with LD increased, the nature and methods of assistance were enhanced and refined. A review conducted among 650 HEIs in the United States showed that support given to students with LD include: testing accommodations, individual mentoring, tutoring and enhancing study skills and 
learning habits (Stodden, Whelley, Chang, \& Harding, 2001).

Services at the support centers for students with LD offer diverse methods and accommodations (Lipka, Forkush, $\&$ Meer, 2019). However, not every student with LD receives all the support services, rather they are provided according to the severity of the disability and according to the student's abilities. Support is provided individually or in groups, and incorporates both emotional aspects and strategies for dealing with the study material. Support is provided by professionals or mentors, and the use of assistive technologies (Einat, 2004).

In general, support center activities include guidance and counseling regarding the admission process into the HEI; diagnostic tests to determine accommodations; admission preparation summer schools; courses and workshops for improving learning skills; individual and group mentoring and support during studies; emotional support; assistive technologies such as computers, state-of-the-art equipment and specific learning-assistance software to help with reading, translating, recording, scanning etc. More specifically, the support centers provide a variety of services listed below:

1) Reading and writing assistance-a key area of support, alongside integrating these into the cognitive and social fields. This is done through special reading-writing workshops that bring about significant improvement in the academic performance of students with LD (Dahan, Meltzer, \& Finkelstein, 2011).

2) Academic skills-students are also helped with academic skills development. Through the support center, they receive help with preparing for exams, with time and resource management, gathering material, eliciting their preferred learning styles, library work, memory enhancement and presentation skills.

3) Support for English-A special assistance in English is given, since mastery of English is crucial for academic success and most students with LD have difficulty learning a foreign language, especially among Arab students, for whom English is a third language. The programs focus on strategies for linguistic, cognitive, and metacognitive English reading. Research has shown that the programs have improved the students' reading and reading comprehension in English as well as enhancing their sense of self-efficacy.

4) Strategies for learning mathematics and science-students with LD often struggle to understand mathematical language, logical thinking, mastery of the multiplication table, formula memorization, terms representing quantitative concepts etc. Hence, support centers also provide unique strategies that help with overcome these problems through representation via other senses (auditory or multi-dimensional visual information) viewing information in different formats (text, images, tables, animation and video) and displaying a variety of information through technology.

5) Emotional support-in addition to the academic support, some centers also provide meaningful emotional support to promote academic achievements. This support helps students recognize their learning disability and cope with the frustration it causes in the academic setting. The support provides students with tools and the mental resilience to cope with their daily difficulties and succeed in realizing their learning potential.

6) Individual coaching-some centers have coaches for individual guidance designed to develop effective mechanisms for coping with attention deficit problems and difficulties with general organization.

7) Mentoring-most support centers provide learning assistance via student mentors, some with learning disabilities but most without. The mentors clarify academic content and this helps students cope with their specific disability. The wide range of disabilities and the presence of students with LD in all departments require personal attention and flexibility in the assistance provided.

8) Social support-at the support center students with LD meet students in the same situation. As a result, they no longer feel they are alone and see that they aren't the only ones dealing with a disability. The encounters empower them, build their confidence and help them cope with their difficulties.

9) Preparation for integration into the job market (found only in some support centers).

\subsection{Learning Disabilities Among Arab Students in HEI}

Arab students with LD in HEIs in Israel face even many difficulties. Until recently, diagnosis and treatment of learning disabilities within the Arab education system was complicated, both because of a lack of valid and well-adapted diagnostic tools in Arabic and a shortage of Arabic-speaking professionals. As a result, Arabic-speaking children with LD were not diagnosed at all, thus, did not receive supportive services or were mislabeled, which impaired them both socially and psychologically. Often, these children were diagnosed at a later stage of their development, which means that effectively treating the problems had a smaller chance of success (Albatti et al., 2017).

Although learning disabilities have been researched extensively, information about the phenomenon in Arab 
society is very limited. Yet, the prevalence of learning disabilities among students in Arab society is high (Albatti et al., 2017). Probably due to the traditional nature of Arab society which embraces collectivism and places less emphasis on the individual, there was relatively low awareness of learning disabilities and their implications (Jabareen-Taha \& Taha, 2016). Until the last decade, even Arab students studying education, teaching and educational counseling did not receive appropriate training for a proper understanding of LD, and this lack of knowledge is still evident (Jabareen-Taha \& Taha, 2016). Relatively speaking, Arab society's coping with learning disabilities is still deficient in light of this lack of awareness and knowledge in HEIs, among professionals and, of course, among the families of children with LD.

However, over the last ten years, awareness of the needs of school students with LD in Arab society has risen, and nowadays, the Israeli government provides assistance in this regard to almost all elementary, middle and high schools in the Arab sector, allowing detection, diagnosis and treatment for these children. At the same time, there has been a significant increase in the integration of Arabs into Israel's HEIs (Ali, 2013). In addition to being a place for acquiring education and even a profession, HEIs constitute a milieu that encourages social mobility - a way to reduce the social and employment gap in the Arab sector. With this in mind, a wide variety of resources have been invested, including support for Arab students in the form of academic, social and personal guidance in diverse disciplines (Ali \& Daas, 2018). As a result, Arab students in HEI can function as emissaries of change in the society they represent, and contribute to the Arab sector's political, economic and social integration into Israeli society. During their studies, Arab students attend class with Jewish students as well as students from other sectors, and thus can express themselves and this is a significant opportunity for them to integrate in society (Ali \& Daas, 2018).

Data from the Council of Higher Education (CHE) in 2018 indicate that a gap remains, and that a higher proportion of Jews meet the requirements for college admission than do Arabs. This gap begins in elementary and high schools, as reflected in the significantly lower percentages of Arab students eligible for a full matriculation certificate. The psychometric exam required for HEI admission is another obstacle for the Arab sector, as seen in the significant gap in scores between Arabs and Jews (CHE, October 2018) and so the need for assistance has emerged.

\subsection{Support Centers for Arab Students in Higher Education Institutions}

In recent years, various HEI have developed support programs for Arab students in general and for those with LD in particular. As mentioned above, most HEI in Israel now seem to have frameworks for diagnostic tests and accommodations for students with LD. Every student with LD (no matter which sector the student comes from) go through a diagnostic assessment. Despite the awareness of learning disabilities and the difficulties they pose in higher education, there used to be no support for the particular difficulties experienced by Arab students with LD. For example, during lectures, lecturers are often unaware of the language difficulties involved, and do not think of accommodations such as adapting difficult words for students with a LD whose mother tongue is Arabic, thus, might find it hard to understand specific complicated word (Ali, 2013).

Currently, Israel's CHE is making great efforts to assist Arab students with LD and, together with the National Center for Evaluation, have jointly developed a system for diagnosing learning disabilities in Arabic, in order to help Arabic-speaking students with LD receive appropriate accommodations for academic and psychometric tests. In addition, the CHE data show that $10 \%$ of the Arab sectors are diagnosed with learning disabilities, but only $2 \%$ of them receive testing accommodations. This gap is significant in explaining the Arab public's lack of awareness of learning disabilities and there is also probably a concern among Arab students about being negatively labeled and so they may also sometimes refrain from being diagnosed in the first place (CHE, October 2018).

The implementation of support for Arab students with LD varies from one institution to another. For example, one university in the center of the country helps students with LD through social engagement and student mentors. Another support center offers free learning skills courses. At a third university, tutors provide support for students who need it, but the learning skills courses are not yet solid enough. At another university, the support center provides a laptop for students with dysgraphia during tests and some support centers at other universities and colleges, provide reading software and various study aids (Ali, 2013), as well as allowing extra time in exams and individual support during studies.

A holistic program for access to higher education for Arab society has been implemented on 2018 in Israel. The program requires that every HEI must have support units suited Arab students' needs (Hendin \& Ben-Rabi, 2015). The holistic support program for Arab students, together with programs for helping students with LD, is a potentially significant force that also serves to support the integration of all Arab students into HEI, helping them to overcome difficulties they experience in general, focusing on students with LD. 
The program involves a variety of approaches to assist Arab students. First, there is pre-academic preparation. This support provides Arab students with guidance and assistance on a personal, social and educational level, and scholarships are also awarded to students who excel. Second, the program includes guidance for the Arab students' first encounter with the academic world. Prior to the academic year it prepares students for their studies. Third, when students arrive, their absorption on campus is guided, with a personal, social and educational program, tailored to the students' needs, especially in the first year of study. Fourth, employment guidance is provided as part of the program towards the end of studies to help students consider their next academic and/or occupational step. In addition, the program offers scholarships in return for volunteering during studies as well as scholarships for outstanding Arab students in postgraduate studies and outstanding Arab faculty members (Al-Haj, 2003).

In addition, accommodations are provided for Arab HEI students, including eligibility for accommodations mainly in preparatory courses and in some places for the first and/or all years of study - an extra 15 minutes for exams, use of a Hebrew-Arabic dictionary, if necessary. The accommodations are made automatically according to the nationality registered in the HEI system (Hendin \& Ben-Rabi, 2015).

\subsection{The Current Study}

There is almost no study that have examined the relationship between support for Arab students with LD in HEI and its actual impact on their achievements and general functioning and feelings. Accordingly, the current study sought to conduct a preliminary examination of the contribution of support centers to Arab students with LD and to how they cope with academic tasks. The main research question was whether support centers for students with LD Arab students improve their academic achievements and integration into these institutions, in the eyes of the students themselves. The question was examined via interviews with students studying at two HEI in Israel, through a qualitative analysis.

\section{Method}

\subsection{Participants}

The study consisted of semi-structured interviews with eight Arab students, three men and five women ranging from the ages of 26 to 31, studying in two HEIs in the north of Israel where there are support centers of one sort or another for Arab students and ones with LD. All participants reported being diagnosed with some learning disability and one student was also diagnosed with a severe concentration deficit. All students were studying for a B.A. - three in education, three in economics and management, and two in social sciences. Some students were in the final year of their B.A. studies while others were in their first or second year. The students agreed to participate and expressed willingness to answer the interview questions.

\subsection{Measures}

Using semi-structured in-depth interviews, we gathered information about the student experience, about their coping with being Arabs diagnosed with a learning disability, about whether they had received academic support and the impact of that support on their studies and academic functioning. The interview questions were mainly about the students' studies, their feelings in terms of their disability while studying, when they were first diagnosed, and the support they received from the institution they attend.

\subsection{Research Procedure}

We reached out to the students through forums for students with LD and the message snowballed, with one student leading to another. The interviews were conducted on campus, and were recorded, then immediately transcribed. The interviews were analyzed in accordance with the principles of qualitative research. The coding into content categories yielded the key themes presented in the findings section. The questionnaire included the following questions: When did you start studying your academic studies? What classes do you take? When were you diagnosed with a learning disability? Tell us a little about the nature of the disability, and how you cope with it. How does the learning disability affect you as a student studying in academia? Do you get support from the academic institution you attend? How and in what ways does the support you receive help you.

\section{Results}

The content analysis of the interviews with Arab students diagnosed with learning disabilities yielded four major themes:

\section{Theme 1: Double difficulty}

The first theme that arises is that these students experience a double difficulty: They reported having to deal first with being speakers of Arabic rather than Hebrew as their mother tongue, and then as students diagnosed with learning disabilities. Thus, it is twice as challenging for them. 
"Even the fact that I'm an Arab doesn't make it easier for me, because I have difficulties with Hebrew anyway, so the difficulty is, of course, double. In other words, I am at a disadvantage to begin with";

"I am dyslexic, and this is in addition to me being Arab- right? So it's very hard to read and write and I'm really trying to overcome that. But I have to make a double effort compared to any other student because of the disability and also because I am an Arab. It's not easy. I am dealing with that, slowly. I get a lot of support from my friends from the other students and from the college, but there's no doubt that it's not simple for me";

"As I said, just the fact that I'm an Arab, like it's this combination that is really hard for me and I see other students who either have no disabilities or else they aren't Arab and are native speakers of Hebrew, and I see how different I am from them, how much more I struggle to survive the degree studies and succeed, and with relative difficulty. My grades are quite mediocre but I know it is a lot for me and I try as much as I can, not to compare myself to others";

"It's really hard for me to express myself in writing and I speak Arabic first, so think about how difficult it is to write in Hebrew as someone who speaks Arabic as well as someone with such a disability. It's crazy. It's really more difficult than usual, for someone who just has a disability or doesn't have one at all."

Theme 2: Lack of awareness of learning disabilities in Arab society

The second theme that emerged from the interview analysis was the lack of awareness in Arab society of learning disabilities and their diagnosis. Interviewees repeatedly reported the lack of awareness and that their diagnosis was made only when they considered applying to academia, whether it was through the psychometric exam or at the beginning of academic studies, which only then became necessary. For example, one student said of this difficulty: “.... in childhood it was really hard, I remember studying as a bad thing. I hated studying. And there was no awareness. When I decided to go to study I had quite a few concerns. Along the way I had to show a lot of determination and creativity to succeed and despite the difficulty, I managed to get outstanding grades last year. In my time there really wasn't awareness of learning disabilities, and as a child I heard more than once that I was lazy or that I was not smart. The combination of learning disabilities and all that this implies affected me as I finished high school without finishing my matriculation exams. I had to complete them afterwards in order to get into higher education";

Another student said: "I was diagnosed only last year, the first year of my degree I managed with great difficulties, and to tell the truth, with that combination, believe me, it was just like that. Last year with the help of a consultation I realized there was a problem and got diagnosed and they even helped me pay for it. Before that, our Arab society has no awareness of these things so it never occurred to me at all";

"The discovery of learning disabilities happened only recently. The moment when I really realized I had learning disabilities was when I took my daughter to a diagnosis about two years ago. Suddenly I saw the difficulties I was experiencing at home as well and realized that this difficulty was there";

"During my childhood, they didn't know anything at all, like it wasn't in my parents' mind at all, even though I had a lot of difficulties in school. But still, and then I did the psychometric test and there I saw there was a problem. My psychometric instructor showed me what might be a disability and I got a diagnosis";

"Last year with the help of college consultations here I realized there was a problem and got a diagnosis and they also helped me pay for it. With us in Arab society, there is no awareness of these things, so it never occurred to me";

"Look, I got diagnosed and that really helped me understand what I have and what was wrong and also how to get from the college what I needed so it made it much easier for me."

Theme 3: Relief after diagnosis

A third theme deals with the sense of relief that students reported after the diagnosis, feeling that there is support and accommodations in tests, and the recognition of their situation and their difficulty. And with the diagnosis, there comes a sense of relief that helps greatly in continued coping and success.

"My psychometric instructor showed me there may be a disability and I got diagnosed and I'm lucky I did. It really helped me with my psychometric exam and the degree, now that there are accommodations and concessions that make things easier";

"The accommodations are really good for me. Oral exams are an amazing change for me. It's still hard but very different and far more normal for me";

"I was diagnosed with dysgraphia. It is difficult for me to write, it is difficult for me to say things on paper, so I 
have accommodations and I'm allowed oral examinations and such and I am very pleased with that";

"I was diagnosed and that really helped me understand what I had and what was wrong and it also helped me to get from college what I needed, so it made it much easier for me."

Theme 4: Contributions of the assistance offered in support centers

A fourth and final theme that emerged from the interviews relates to assistance from the support centers. It seems that all the students interviewed, without exception, take advantage of them - both the aid provided to Arab students in general and support centers for students with learning disabilities. They report that the support has greatly helped them in their studies as well as personally and emotionally and to a decrease in feelings of loneliness. Stress and despair, and sometimes even with the funding of their studies. Most of them emphasized the personal treatment and connection that is significant to them in the support they receive and the contribution to their academic function specifically and in in general.

Examples of student comments:

"There is a lot of support in college for both Arab students and for students with learning disabilities, I get a lot of support based on my double difficulty"; "But the fact us that I have to make a double effort compared with every other student because of the disability, both because I'm an Arab and because of my disabilities. It's not easy. I deal with it slowly, I get a lot of support from my friends and the college, but it's not easy for me"; There is personal support and personal connection, which I think are the most important thing";

"There is a support program and it caters to students with learning disabilities and ADD, in the transition from college studies to integration into the job market, so that it helps us as students contribute to the community and use what we have acquired and our skills properly.

"There is support provided by the college for Arab students and students with learning disabilities, so I get double support, financially as well, they give us a discount and that really makes it easier to come to study, and as for the disabilities, there are workshops that they give us"; "In the workshops I learn a lot, I get support first from the group and the facilitator. I can share and understand that I am not alone and there are others like me, who are both Arabs and have disabilities and that's okay";

"They work on our identity and with the disability as if it is part of it and not all of who we are, and I was personally touched by that in the workshop";

"We have support for Arab students and I mainly take what I can in terms of accommodations and concessions that make my studies easier, and in terms of money. I know there is support given in a group format and such as well, but I don't relate to that as much, truth be told";

"In truth, we get a lot of support in the college; they help both those who come from the sector and those who are diagnosed. There are some support groups I take part in and they do help me";

"During a crisis while studying for a statistics test, for example, they called me from the center and were there for me; they calmed me down and reminded me of my successes. I knew I had to do the best I could";

"At the support center, they helped me believe that anything is possible, that there are tools for success and that I have to reach out to them for myself, because only I can move my success forward. I learned that it's very important not to be ashamed, learning disabilities don't indicate incompetence"; "Yes, I received [support] throughout my years in college, there is really good college support for both Arab students and those diagnosed with learning disabilities";

"Through the support center I also got a tutor, she gave me study tools but also helped me with much more than studying. I even shared personal matters in my life. The emotional support that is very important for people with a learning disability. It's very important to understand that you aren't alone. Even the atmosphere between classes is very sociable, everyone talks about everything and discusses problems and difficulties. Recently I signed up to be a mentor so I can help others just like they helped me."

\section{Discussion and Implications}

The various support centers and means of assistance contribute greatly to students with LD in HEIs, and this is all the more so for Arab students with LD. Nowadays, there is a greater awareness of their situation and needs and HEIs have many tools to help them both educationally and emotionally, thereby enabling them to realize their personal potential and to advance. In addition, there are HEIs that have designed special projects to provide these students with tools needed to integrate into the job market once they graduate. Continued assistance and support is important, not only because it promotes equality in education, but also because these centers allow students to 
realize their potential despite the difficulties and challenges they face.

The findings of this preliminary study suggest that Arab students diagnosed with LD experience a double difficulty: a difficulty with the Hebrew language as the dominant language in the HEIs in Israel and the inherent difficulty of their learning disability. However, it appears from the interviews that these students receive a great deal of support from their HEI and they describe comprehensive financial, emotional and educational support that help also in the transition to the workforce. In other words, students report multiple difficulties, but also report some relief and recognition of their difficulties and problems and say that the support they receive through concessions and accommodations greatly enhances their academic, emotional and social experience and enables them to study successfully. The support centers help them significantly with their identity, and contribute to the fact that the disability does not completely overshadow their academic learning process.

In addition, according to the literature (see: Ali, 2013; Ali \& Daas, 2018), it seems that in Arab society, there is still relatively low awareness of the presence of learning disabilities and so only a few diagnoses are made in order to identify and respond to difficulties and disabilities. All Arab students reported that they had only been diagnosed for external guidance and assistance from academia and/or academic studies when they wanted to acquire higher education. Moreover, it seems that Arab students who have been diagnosed and discovered the name of the difficulty they experience may report having had difficulties in childhood as well, and express a deep sense of relief when receiving the diagnosis, which is probably due to the thought that is it neither their fault, nor within their control. In addition, they feel that their condition is recognized and others can see and acknowledge their difficulty and thus try to relieve it. All of these boost self-confidence, improve self-image and the formation of their identity and change in this context for the better, and more.

Moreover, analysis of the findings reveals awareness among students who are parents of the underlying cause for their own child's behavior, awareness of the personal difficulties of both the parent and the child. This was only reported by some students, but was still mentioned. The main difficulty that recurred in parents' comments concerned their own difficulty vis-à-vis their child getting organized every day, in the morning in particular. It also emerged that there are common difficulties, as the literature has also shown, concerning children with ADHD, which mainly revolve around the educational and social field and significantly damage their self-image which becomes negative due to the circumstances of the child's life and events due to the difficulties of the disorder that continue appearing over time.

Given the above, from the students' experiences documented in the current study, it appears that support centers for students with LD help Arab students improve their academic achievements and help them even in non-academic aspects. There appears to be great value in advancing students and providing support for Arab students diagnosed with LD that helps them emotionally, socially and in terms of motivation and self-esteem, which, in turn, affect academic achievements. However, students did not mention support given to Arab students with LD that targeting student's later in life, on a personal level and the professional/employment level. There seems to be a need for a more focused response for these students as well as refinement and expansion of the questionnaire in these directions.

One of the limitations of the study is that for some of the participants the interview was too long and there was also a social desire to answer some of the questions in a certain way.

To conclude, the preliminary current study can make a practical contribution to existing and future support centers enabling an understanding of the needs that arise from the students' voices in order to provide a more precise response. We suggest that future studies will include interviews with support centers employees for creating a deeper holistic perspective. This study is preliminary and is not wide-ranging, thus we recommend further research on the subject sampling more participants and more HEIs alongside refining the questionnaire in order to identify more needs and problems related to support centers, as well as validating these preliminary findings. Yet, these findings imply the importance of allocating resources to HEI in order to continuously improve the services provided to students with learning disabilities to support their present advancements and future success.

\section{References}

Albatti, T. H., Alhedyan, Z., Alnaeim, N., Almuhareb, A., Alabdulkarim, J., Albadia, R., \& Alshahrani, K. (2017). Prevalence of ADHD among primary school children. International Journal of Pediatrics and Adolescent Medicine, 4(3), 91-94. https://doi.org/10.1016/j.jpam.2017.02.003

Al-Haj, M. (2003). Higher education among the Arabs in Israel: Formal policy between empowerment and control. Higher Education Policy, 16(3), 351-368. https://doi.org/10.1057/palgrave.hep.8300025

Ali, N. (2013). Representation of Arab citizens in institutions of higher education. Haifa and Jerusalem, Sikkuy: 
Association for the Advancement of Civic Equality (heb).

Ali, N., \& Daas, R. (2018). Higher education among the Arab minority in Israel - representation, mapping, obstacles and challenges. Tel Aviv: Resling (heb).

Alt, M., Hogan, T., Green, S., Gray, S., Cabbage, K., \& Cowan, N. (2017). Word learning deficits in children with dyslexia. Journal of Speech, Language \& Hearing Research, 60(4), 1012-1028. https://doi.org/10.1044/2016_JSLHR-L-16-0036

Al-Yagon, M., \& Margalit, M. (2016). Specific learning disabilities: The Israeli perspective. Learning Disabilities: A Contemporary Journal, 14(1), 39-51. https://doi.org/10.1007/978-3-319-32132-5_806-1

American Psychiatric Association. (1994). DSM-4-Diagnostic and statistical manual of mental disorder. Washington DC: American Psychiatric Association.

American Psychiatric Association. (2013). DSM-5-Diagnostic and statistical manual of mental disorder. Arlington, VA: American Psychiatric Association. https://doi.org/10.1176/appi.books.9780890425596

Artman, L. (2012). Dyslexia and Dyscalculia: Clinical-organic disorders or functional fixation? Hinuch Vesviva [Education and Environment] Seminar Hakibbutzim Yearbook, 34, 9-19

Beck, C. A. J., \& Sales, B. D. (2001). Family mediation: Facts, myths, and future prospects (pp. 100-102). Washington, DC: American Psychological Association. https://doi.org/10.1037/10401-000

Council for Higher $\quad$ Education. $\quad$ (2018). $\quad$ Retrieved from https:/che.org.il/wp-content/uploads/2019/04/\%D7\%AA\%D7\%9B\%D7\%A0\%D7\%99\%D7\%AA-\%D7\%9 5\%D7\%AA \%D7\%AA-\%D7\%9C\%D7\%94\%D7\%A0\%D7\%92\%D7\%A9\%D7\%94-\%D7\%9C\%D7\%97\%D 7\%91\%D7\%A8\%D7\%94-\%D7\%94\%D7\%A2\%D7\%A8\%D7\%91\%D7\%99\%D7\%AA.pdf

Couzens, D., Poed, S., Kataoka, M., Brandon, A., Hartley, J., \& Keen, D., (2015). Support for students with hidden disabilities in universities: A case study. International Journal of Disability, Development \& Education, 62(1), 24-41. https://doi.org/10.1080/1034912X.2014.984592

Dahan, A., Meltzer, Y., \& Finkelstein, G. (2011). Changes in the integration of students with learning disabilities in higher education in Israel. In J. Jabisher, J. Laser, \& S. Reiter (Eds.), Mixtures: Educational and social systems (pp. 344-315). Haifa: Ahva Pub (heb).

Dahan, A., Meltzer, Y., \& Hadas-Lidor, N. (2010). Voices of the past and present: The self perception of students with learning disabilities as writers (at the beginning of preparatory and after the first semester) of their academic studies. Issues in Special Education and Rehabilitation, 24(1), 23-41.

Dohla, D., \& Heim, S. (2016). Developmental dyslexia and dysgraphia: What can we learn from the one about the other? Frontiers in Psychology, 6, article 2045. https://doi.org/10.3389/fpsyg.2015.02045

Einat, A. (2004). Integrating the learning disabled in academia. In A. Maor, (Ed.), Affirmative action and assuring representation in Israel. Tel Aviv: Ramot Publications (heb).

Einat, A., \& Einat, T. (2004). Indictment-Learning disabilities, dropouts and delinquency. Hakibbutz-Hameuhad Publishing (heb).

Engel-Yeger, B., Nagauker-Yanuv, L., \& Rosenblum, S. (2009). Handwriting performance, self-reports, and perceived self-efficacy among children with dysgraphia. American Journal of Occupational Therapy, 63(2), 182-192. https://doi.org/10.5014/ajot.63.2.182

Erhardt, R. P., \& Meade, V. (2005). Improving handwriting without teaching handwriting: The consultative clinical reasoning process. Australian Occupational Therapy Journal, 52(3), 199-210. https://doi.org/10.1111/j.1440-1630.2005.00505.x

Friedmann, N., \& Coltheart, M. (2016). Types of developmental dyslexia. In A. Bar-On, \& D. Ravid (Eds.), Handbook of communication disorders: Theoretical, empirical, and applied linguistics perspectives (pp. 1-37). Berlin: De-Gruyter Mouton.

Hadley, W., Hsu, J., Addison, M., \& Talbott, D. (2020). Marginality and mattering: The experiences of students with learning disabilities on the college campus. In Accessibility and Diversity in Education: Breakthroughs in Research and Practice (chap. 20, pp. 390-403). IGI Global pub. https://doi.org/10.4018/978-1-7998-1213-5.ch020

Hendin, A., \& Ben Rabi, D. (2015). Chancellors' program of the integration of Arabs, Druze and Circassians in higher education. Meyers-Joint-Brookdale. Retrieved from http://din-online.info/pdf/mb12.pdf 
Howarth, S., Morris, D., Newlin, M., \& Webber, M. (2014). Health and social care interventions, which promote social participation for adults with learning disabilities: A review. British Journal of Learning Disabilities, 44, 3-15. https://doi.org/10.1111/bld.12100

Jabareen-Taha, S., \& Taha, H. (2016). Learning disabilities: Current policy and directions for community involvement among the Arab community in Israel. Educational Research and Reviews, 11(14), 1279-1287. https://doi.org/10.5897/ERR2016.2831

Lipka, O., Forkush, A., \& Meer, Y. (2019).Academic support model for post-secondary school students with learning disabilities: student and instructor perceptions. Journal of Inclusive education, 23(2), 142-157. https://doi.org/10.1080/13603116.2018.1427151

Margalit, M. (2014). Learning disabilities: a neuro-developmental model 15 years on. Mifgash Le'avoda Hinuchit-Sozialit [Encounter for Educational-Social Work], 22(39), 15-34.

Margalit, M., Brezhnitz, T., \& Aharoni, M. (1998). Examination of the treatment of students with learning disabilities in institutions of higher education (Summative report). Council for Higher Education.

Rapin, A (2016). Dyscalculia and the calculating brain. Pediatric Neurology, 61, 11-20. https://doi.org/10.1016/j.pediatrneurol.2016.02.007

Roer-Stryar, D. (2003). Empowering students with learning disabilities. Society and Welfare, 23(4), 474-455.

Showers, A. H., \& Kinsman, J. W. (2017). Factors that contribute to college success for students with learning disabilities. Learning Disability Quarterly, 40(2), 81-90. https://doi.org/10.1177/0731948717690115

Stodden, R. A., Whelley, T., Chang, C., \& Harding, T. (2001). Current status of educational support provision to students with disabilities in postsecondary education. Journal of Vocational Rehabilitation, 16(3-4), 189-198.

Trigger, G., Egozi, S., Doron, N., \& Elharar, A. (2003). Self-esteem in students with learning disabilities. Educational Counseling, 12, 132-119.

Weis, R., Speridakos, E. C., \& Ludwig, K., (2014). Community college students with learning disabilities: Evidence of impairment, possible misclassification, and a documentation disconnect. Journal of Learning Disabilities, 47(6), 556-568. https://doi.org/10.1177/0022219413483175

Zeng, W., Ju, S., \& Hord, C. (2018). A Literature review of academic interventions for college students with $\begin{array}{llll}\text { learning disabilities. Learning Disabilities } & \text { Quarterly, 41(3), 159-169. }\end{array}$ https://doi.org/10.1177\%2F0731948718760999

Ziv, A. (2014). Students with learning disabilities - Conceptualization, inclusion and implications for the role of the counselor, educational counseling today: Food for thought and practice. Bnei Brak: Sifriat Poalim, 159-206.

\section{Copyrights}

Copyright for this article is retained by the author(s), with first publication rights granted to the journal.

This is an open-access article distributed under the terms and conditions of the Creative Commons Attribution license (http://creativecommons.org/licenses/by/4.0/). 